\title{
Whole Linted Cottonseed as a Forage Substitute: Fiber Effectiveness and Digestion Kinetics ${ }^{1,2}$
}

\author{
D. I. Harvatine, ${ }^{3}$ J. E. Winkler, M. Devant-Guille, ${ }^{4}$ \\ J. L. Firkins, N. R. St-Pierre, B. S. Oldick, ${ }^{5}$ and M. L. Eastridge \\ Department of Animal Sciences, \\ The Ohio State University, Columbus, 43210
}

\begin{abstract}
Six ruminally and duodenally cannulated Holstein cows were used in a $6 \times 6$ Latin square design to 1) evaluate the potential interaction in effectiveness of neutral detergent fiber (NDF) from whole cottonseed (WCS) when it was substituted for forage NDF (FNDF) and fed with ground $(\mathrm{G})$ or steam-flaked (SF) corn and 2 ) to determine whether the kinetic properties of NDF digestion further clarify the effectiveness of WCS. The six dietary treatments were: forage control with $\mathrm{G}$ corn ( $21 \% \mathrm{FNDF}), 5 \%$ WCS with G or SF corn (18\% FNDF), $10 \%$ WCS with G or SF corn (15\% FNDF), and $15 \%$ WCS with G corn ( $12 \%$ FNDF). Based on chewing activity, the NDF from WCS was estimated to be $84 \%$ (SE $=36 \%)$ as effective as alfalfa silage NDF. Decreasing passage and digestion rates of potentially digestible NDF with increasing WCS increased the evacuated pool size of ruminal DM, apparently explaining the similar ruminal mat consistency among treatments. Measures of effectiveness of WCS treatments did not interact with corn source. Fluid dilution rate was estimated based on a two-compartment model describing Co dilution, but no treatment differences were detected. There was a strong linear bias for estimates of ruminal NDF digestibility based on a single compartment model using the digestion rate of potentially digestible NDF and the passage rate of either indigestible NDF or digestible NDF when compared with NDF digestibility calculated using duodenal flows. Although further verification is
\end{abstract}

\footnotetext{
Received June 8, 2001.

Accepted February 5, 2002.

Corresponding author: J. L. Firkins; e-mail: firkins.1@osu.edu.

${ }^{1}$ Salaries and research support were provided by state and federal funds appropriated to the Ohio Agricultural Research and Development Center, The Ohio State University. Manuscript number 14-

${ }^{2}$ Additional research support was provided by the Ohio Dairy Farmers Federation Dairy Research Fund; Pennfield Feeds, Lancaster, PA; and Cotton Incorporated, Cary, NC.

${ }^{3}$ Current address: Agway Feed and Nutrition, 512 West King St, Shippensburg, PA 17257.

${ }^{4}$ Current address: 25300 Tàrrega, Lleida, Spain.

${ }^{5}$ Current address: 52185 Brendon Hills Drive, Granger, IN 46530.
} 01AS. needed, these digestion and passage kinetics help explain why WCS are effective at stimulating chewing during eating and rumination.

(Key words: effective fiber, passage rate, rumen, whole cottonseed)

Abbreviation key: CNDF = NDF from cotton products, DNDF = digestible NDF, FCG = forage control with ground corn, $\mathbf{F N D F}=$ forage NDF, $\mathbf{G}=$ ground corn, $\mathbf{H G}=$ high cottonseed with ground corn, INDF = indigestible NDF, $\mathbf{k}_{\mathbf{d}}=$ fractional rate of digestion, $\mathbf{k}_{\mathbf{p}}$ $=$ fractional rate of passage, $\mathbf{L G}=$ low cottonseed with ground corn, LSF = low cottonseed with steam-flaked corn, $\mathbf{M G}=$ medium cottonseed with ground corn, $\mathbf{M S F}$ = medium cottonseed with steam-flaked corn, $\mathbf{S F}=$ steam-flaked corn, WCS $=$ whole cottonseed .

\section{INTRODUCTION}

Physically effective fiber is the fraction of the feed that stimulates chewing; chewing stimulates saliva secretion, which buffers acidic end products of fermentation and helps prevent depressions in DMI, ruminal motility, microbial yield, and fiber digestibility (Allen, 1997). Traditionally, physically effective fiber requirements of cattle were met using forages; however, fibrous byproducts may provide an alternate means of increasing the physically effective fiber concentration of the diet. Based on chewing response, whole cottonseed (WCS) appears to be the most effective fiber source from byproduct feeds (Clark and Armentano, 1993; Mooney and Allen, 1997). Additionally, physical effectiveness can be evaluated based on ruminal mat consistency, which alters ruminal retention time of feeds, contributes to differences in effective fiber, and stimulates rumination (Weidner and Grant, 1994a; Mertens, 1997; Allen and Grant, 2000).

Byproduct feeds usually have faster passage rates and slower digestion rates than do forages (Firkins, 1997). Unfortunately, the passage rate of particulate matter in the rumen is hard to estimate, and more progress is needed for use in ruminal models (Firkins et al., 1998). External markers used to evaluate passage 


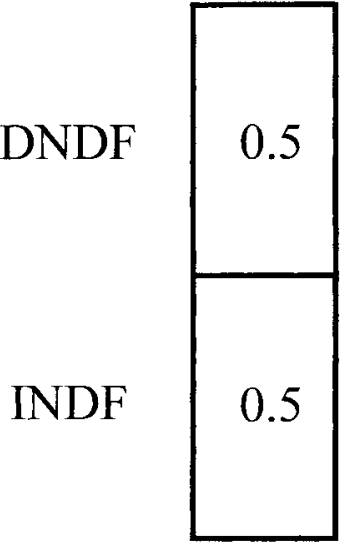

$\mathrm{k}_{\mathrm{p}}, / \mathrm{h}$
0.040

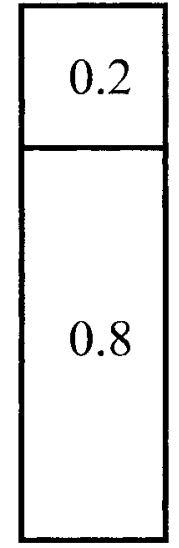

0.045

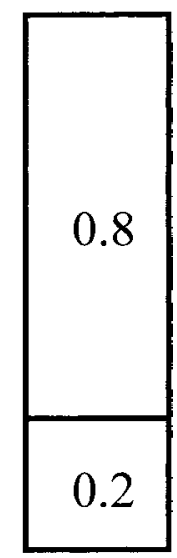

0.030
Figure 1. Why the fractional passage rate $\left(\mathrm{k}_{\mathrm{p}}\right)$ of potentially digestible (DNDF) and indigestible (INDF) NDF could differ. If three particle fractions (bars) each with $1 \mathrm{~g}$ of NDF are assumed to have varying $\mathrm{k}_{\mathrm{p}}(0.040,0.045$, and $0.030 / \mathrm{h})$ and DNDF and INDF proportions $(0.2$, 0.5 or 0.8 ), the average particle $\mathrm{k}_{\mathrm{p}}$ would be $0.038 / \mathrm{h}$, but the weighted average $\mathrm{k}_{\mathrm{p}}$ would be $[(0.5 \times 0.040)+(0.2 \times 0.045)+(0.8 \times 0.030)] /(0.5$ $+0.2+0.8)=0.035 / \mathrm{h}$ for DNDF and $[(0.5 \times 0.040)+(0.8 \times 0.045)+$ $(0.2 \times 0.030)] /(0.5+0.8+0.2)=0.041 / \mathrm{h}$ for $\mathrm{INDF}$.

rate mark both potentially digestible (DNDF) and indigestible (INDF) fractions of NDF, whereas ruminal digestibility of only the DNDF (not INDF) fraction is limited by passage rate $\left(\mathbf{k}_{\mathbf{p}}\right)$. Although both fractions are within a particle and thus have the same $\mathrm{k}_{\mathrm{p}}$, the distribution of particles with different concentrations of DNDF relative to INDF could cause differences in $k_{p}$ of DNDF and INDF to be aggregated over all ruminal particulate fractions (see Figure 1). Although Firkins et al. (1998) argued that DNDF could pass from the rumen at a rate different than that of INDF, few direct comparisons have been made because duodenal cannulation would be required. Improved estimation of $\mathrm{k}_{\mathrm{p}}$ of DNDF from forages and byproducts should help explain differences in digestibility but also in properties affecting rumination activity.

Past research with soybean hulls (Weidner and Grant, 1994a) and wet corn gluten feed (Allen and Grant, 2000) showed that byproducts interacted with forage to increase ruminal mat consistency, decrease the passage rate of the byproduct, increase rumination activity, and increase ruminal extent of digestion. Coppock et al. (1985) speculated that linters entrap WCS in the fibrous ruminal mat so that WCS are chewed during rumination. If decreased clearance of feed DM and reduced feed particle size (WCS replacing forage) alter ruminal volumes of DM or fluid, then this could impact ruminal mat consistency or chewing. Little in- formation is available to characterize the possible interactions between forage and other byproduct feeds, such as WCS, on ruminal mat consistency and chewing response, which probably explains the increased effectiveness of NDF of WCS as forage particle size decreased (Mooney and Allen, 1997). We postulated that a similar increase in effectiveness of WCS by cows might occur in response to increased starch availability, similar to a response in chewing time with increased concentrate allocation (Robinson and McQueen, 1997). Thus, the objectives of this research were to 1 ) evaluate the potential interaction between forage and WCS on measures of fiber effectiveness (ruminal mat consistency and chewing) when WCS was substituted for forage and fed with corn differing in ruminal starch degradability, and 2) determine whether kinetic parameters of NDF digestion further clarify the role of effective fiber from WCS.

\section{MATERIALS AND METHODS}

\section{Animals, Treatments, and Experimental Design}

Six primiparous Holstein cows $(\mathrm{BW}=517 \mathrm{~kg})$ fitted with ruminal and simple $\mathrm{T}$ duodenal cannulas were arranged in a $6 \times 6$ Latin square design. A description of the cows' feeding and management systems, including the experimental diets and loss of one observation, are described in a companion paper (Harvatine et al., 2002). The forage control diet (FCG) with no WCS addition contained the NRC (1989) recommendation of $21 \%$ forage NDF (FNDF). The WCS diets contained WCS at low (L), medium (M), or high $(\mathbf{H})$ concentrations (5, 10 , and $15 \%$ of dietary DM, respectively). In diets with ground $(\mathbf{G})$ corn, alfalfa silage was replaced with WCS on an NDF basis to achieve diets with $18 \%$ FNDF (LG), $15 \%$ FNDF (MG), and 12\% FNDF (HG). Linted cottonseed hulls were added to the diets in slightly different amounts during each period to balance NDF from forage and cotton products. To evaluate the potential interaction of starch availability and level of forage substitution, the G corn in the LG and MG diet was replaced with steam-flaked (SF) corn (LSF and MSF diets).

\section{Sampling and Laboratory Analysis}

Periods consisted of $21 \mathrm{~d}$, with $\mathrm{d} 1$ through 9 serving as an adjustment period and d 10 through 21 as the data collection period. Diets were prepared once daily as TMR and fed twice daily in equal proportions at 0600 and $1800 \mathrm{~h}$ for ad libitum intake, and digesta flow was measured using $\mathrm{Cr}_{2} \mathrm{O}_{3}$ as described previously (Harvatine et al., 2002). Cows were housed in a conventional tie-stall barn, milked at 0530 and $1600 \mathrm{~h}$ daily, and allowed access to a concrete lot before milking, except on days when chewing activity was being monitored. 
Cows were monitored for chewing activity for a continuous 24-h period on the first day (d 10) of each collection period (Weidner and Grant, 1994b). Every 5 min, cow activity was recorded as standing or lying, and chewing activity was defined as resting, eating, or ruminating. Total time (minutes) spent on each activity was quantified by multiplying the total number of observations for that activity by five. No chewing observations were made while the cows were held in the holding pen or milked in the parlor (average time of $57 \mathrm{~min}$ per period). Values for chewing were adjusted proportionally to a 24 -h basis [(measured time spent chewing $\times$ $24) /(24$ - fraction of an hour in holding pen)].

Ruminal mat consistency was measured at 2 and 6 $\mathrm{h}$ after the a.m. feeding on $\mathrm{d} 11$ and at $4 \mathrm{~h}$ after the a.m. feeding on d 12 (Weidner and Grant, 1994a). Weights $(462 \mathrm{~g})$ were placed into the ventral rumen $2 \mathrm{~h}$ before the first measurement. After allowing the ruminal mat to stabilize for $2 \mathrm{~h}$, a counter weight $(1.365$ $\mathrm{kg}$ ) was applied outside the rumen, and the distance that the ruminal weight ascended was recorded every $20 \mathrm{~s}$ for $9 \mathrm{~min}$. Rate of cumulative ascension at 1, 2, 5, and 9 min was calculated. Data were averaged per cow per period.

Passage rates of WCS and alfalfa silage were determined using $\mathrm{YbCl}_{3} \cdot 6 \mathrm{H}_{2} \mathrm{O}$. Whole cottonseed and alfalfa silage were marked separately with $\mathrm{Yb}$ using the method described by Bowman et al. (1991). The Yb$\mathrm{Cl}_{3} \cdot 6 \mathrm{H}_{2} \mathrm{O}$ was dissolved in $0.1 \mathrm{~N}$ acetic acid and poured over the feed and stirred. The feed was soaked for 24 $\mathrm{h}$ and then rinsed three times with $0.1 \mathrm{~N}$ acetic acid and then twice with distilled $\mathrm{H}_{2} \mathrm{O}$. Feed was squeezed by hand between rinses to remove as much fluid as possible. The wet $\mathrm{Yb}$-labeled feed was divided into equal doses and frozen. The Yb-labeled alfalfa was thawed and dosed prior to the a.m. feeding $(0600 \mathrm{~h})$ on $\mathrm{d} 13$ of each period, and the Yb-labeled cottonseed was dosed before the a.m. feeding $(0600 \mathrm{~h})$ on $\mathrm{d} 18$ of each period. After dosing through the ruminal cannula, the ruminal contents were mixed by hand. Ruminal samples were taken at $0 \mathrm{~h}$ (for background correction) and at 1, 2, 4, $6,9,12,18,24$, and $36 \mathrm{~h}$ postdosing. During sampling, ruminal contents were removed from different parts of the rumen until $600 \mathrm{ml}$ was collected. Contents were mixed, and a subsample was squeezed through two layers of cheesecloth and dried at $55^{\circ} \mathrm{C}$. Extra contents were returned to the rumen. Dried samples were ground to pass through a 2-mm screen (Wiley mill, Arthur H. Thomas, Philadelphia, PA). The samples were analyzed for $\mathrm{Yb}$ using a procedure described by Ellis et al. (1982). Samples (2 g) were ashed and then dissolved in a solution containing $3 \mathrm{~N} \mathrm{HCl}, 3 \mathrm{~N} \mathrm{HNO}_{3}$, and $1.91 \mathrm{~g} / \mathrm{L}$ of $\mathrm{KCl}$. After vortexing at 0 and $6 \mathrm{~h}$, the ash was allowed to settle overnight. The fluid was ana- lyzed for $\mathrm{Yb}$ concentration using atomic absorption spectroscopy with a nitrous oxide flame and standard conditions described by the manufacturer (model SpectrAA 220; Varian Australia, Ltd., Mulgrave, Australia).

To determine liquid passage rates, a 50-ml solution of CoEDTA (Uden et al., 1980) was pulse-dosed through the ruminal cannula at $0600 \mathrm{~h}$, before the a.m. feeding on d 18 of each period. After dosing, ruminal contents were mixed thoroughly by hand. Ruminal contents $(1000 \mathrm{ml})$ were sampled as described previously at $0 \mathrm{~h}$ (for background Co correction) and then at 20 and 40 min and 1, 2, 4, 6, 9, 12, 18, 24, and $36 \mathrm{~h}$ postdosing. A subsample was squeezed through two layers of cheesecloth, and the fluid portion was frozen. Extra contents and fluids were then returned to the rumen. After thawing, the ruminal fluid was mixed and centrifuged at $27,000 \times g$ at $4^{\circ} \mathrm{C}$ for $20 \mathrm{~min}$. The supernatant and dose were analyzed for Co concentrations by atomic absorption spectrophotometry (Uden et al., 1980).

Ruminal contents were completely evacuated at $2 \mathrm{~h}$ postfeeding and $2 \mathrm{~h}$ before feeding on d 20 and 21 , respectively, of each period (Dado and Allen, 1995). To aid in proper subsampling, the total contents were squeezed by hand to separate solids and liquids. The liquid portion was strained through a wire mesh screen (5-mm opening) to remove additional solids, which were composited with squeezed solids. A $10 \%$ subsample (by weight) of the solids and a $10 \%$ subsample of the liquid were taken and reconstituted before freezing. The rest of the ruminal contents was returned to the cow within 30 min of initiating evacuation. After thawing, a 1.5-kg subsample of the reconstituted ruminal digesta sample was dried at $55^{\circ} \mathrm{C}$, and moisture loss was used to estimate ruminal fluid volume, assuming a density of ruminal fluid of $1.0 \mathrm{~kg} / \mathrm{L}$. Dried digesta samples from both evacuations were composited within cow and period on a weighted DM basis, ground to pass through a $2-\mathrm{mm}$ screen, and analyzed for DM and OM according to AOAC (1990). The concentration of NDF was determined using the method described by Van Soest et al. (1991) using hot ethanol, $8 M$ urea, and heat stable $\alpha$ amylase (Sigma A3306; Sigma Chemical Co., St. Louis, MO). The concentration of INDF in the ruminal digesta, feed offered, orts, and duodenal samples was determined by 120 -h in vitro fermentation in buffered rumen media without the addition of pepsin (Dado and Allen, 1995).

\section{Calculations}

The methods of Dado and Allen (1995), based on INDF rumen pool size, were used to estimate NDF digestion kinetics. In this procedure, a steady-state and a single compartment model are assumed. Ruminal pool 
size of INDF was calculated as the average rumen DM pool size multiplied by the INDF concentration of ruminal digesta samples. Intake and duodenal flow of INDF were calculated similarly. The technique of Dado and Allen (1995) assumes that the intake of INDF (feed offered corrected for orts) should equal duodenal flow of INDF. To test this assumption, the $\mathrm{k}_{\mathrm{p}}$ of INDF was calculated using the following two equations:

$$
\begin{aligned}
\text { INDF } k_{\mathrm{p}}\left(\mathrm{h}^{-1}\right)= & (\mathrm{INDF} \text { intake/ruminal INDF } \\
& \text { pool size }) / 24
\end{aligned}
$$

INDF $\mathrm{k}_{\mathrm{p}}\left(\mathrm{h}^{-1}\right)=$ (duodenal INDF flow/ruminal INDF pool size)/24

The duodenal flow was calculated with chromic oxide (Harvatine et al., 2002). The concentration of DNDF was calculated as total NDF - INDF. Passage rate of DNDF can be calculated as below (Firkins et al., 1998):
DNDF $\mathrm{k}_{\mathrm{p}}\left(\mathrm{h}^{-1}\right)=$ (duodenal DNDF flow/ruminal DNDF pool size)/24

After $k_{p}$ of DNDF has been determined, the digestion rate $\left(\mathbf{k}_{\mathbf{d}}\right)$ of DNDF can be calculated as intake rate of DNDF minus the $\mathrm{k}_{\mathrm{p}}$ of DNDF (Firkins et al., 1998):

$$
\begin{aligned}
\mathrm{DNDF} \mathrm{k}_{\mathrm{d}}\left(\mathrm{h}^{-1}\right)= & {[(\mathrm{DNDF} \text { intake/24)/ruminal DNDF pool }} \\
& \text { size }]-\mathrm{k}_{\mathrm{p}} \text { of DNDF }
\end{aligned}
$$

The $k_{p}$ of DNDF [3] must be calculated using duodenal flow measurement; that is, no relationship for INDF as in equations [1] and [2] exists for DNDF because considerable but varying amounts of DNDF get degraded in the rumen. To avoid the duodenal flow measurements, some researchers have assumed that the $k_{p}$ of DNDF from equation [3] can be approximated using the $k_{p}$ of INDF from equation [1]. If the $k_{p}$ of DNDF is calculated (or assumed equivalent to the $k_{p}$ of INDF), $\mathrm{k}_{\mathrm{d}}$ can be solved using equation [4], and then ruminal NDF digestibility can be calculated:

Apparent ruminal NDF digestibility $(\%)=$ $(\mathrm{DNDF}$ intake/NDF intake $) \times\left[\mathrm{k}_{\mathrm{d}} /\left(\mathrm{k}_{\mathrm{d}}+\mathrm{k}_{\mathrm{p}}\right)\right] \times 100$

If the $\mathrm{k}_{\mathrm{p}}$ of INDF and the $\mathrm{k}_{\mathrm{p}}$ of DNDF are not equivalent, then the substitution of the $k_{p}$ of INDF for the $k_{p}$ of DNDF in equation [5] would affect the accuracy of the NDF digestibility estimation. Moreover, the estimate of $\mathrm{k}_{\mathrm{d}}$ of DNDF from equation [4], which is needed in equation [5], is also affected by this assumption of equality of $k_{p}$ of INDF and DNDF, further compounding error.

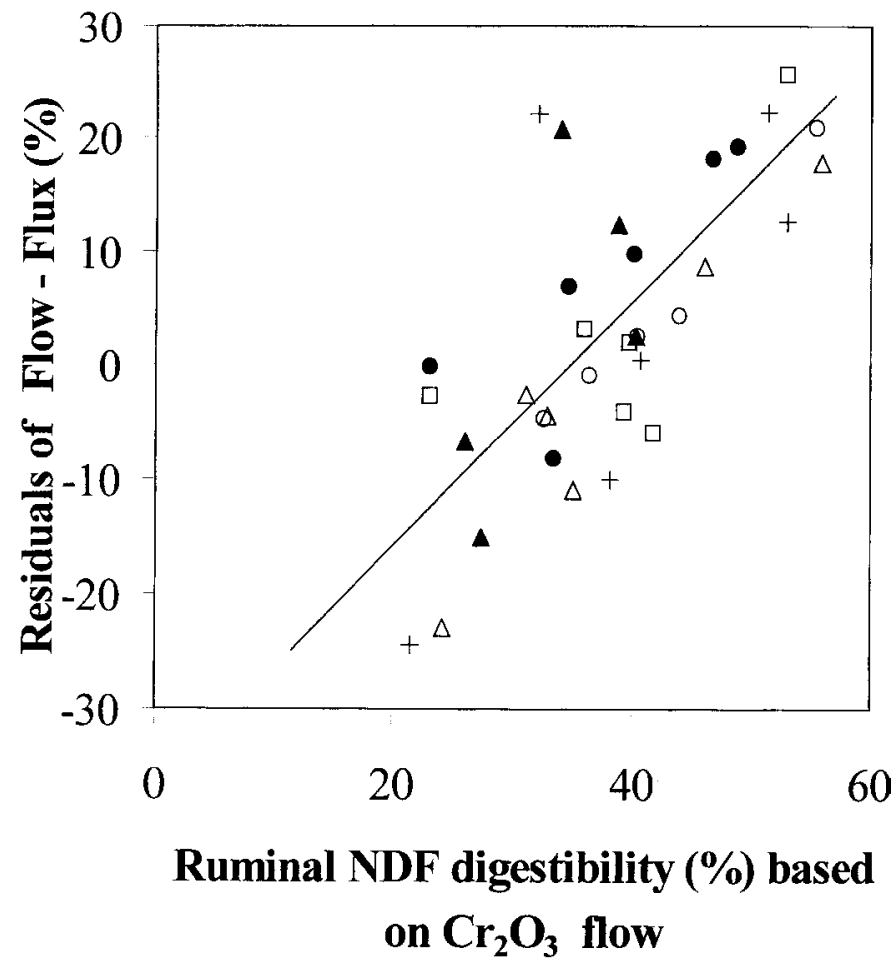

Figure 2. Plot of the residuals of NDF digestibility (\%) calculated based on flow of total NDF at the duodenum using $\mathrm{Cr}_{2} \mathrm{O}_{3}$ as a digesta marker and flux of potentially digestible NDF (DNDF). The passage rate of DNDF (equation [3]) was approximated by the passage rate of indigestible NDF (INDF) from equation [1], and the passage rate of INDF was substituted directly for the passage rate of DNDF in equations [4] and [5]. $\mathrm{y}=1.07 \mathrm{x}(\mathrm{SE}=0.17)-37.2(\mathrm{SE}=6.6)$. Symbols represent the following treatments: forage control with ground corn $(+)$, low cottonseed with ground corn $(O)$, medium cottonseed with ground corn $(\triangle)$, high cottonseed with ground corn $(\square)$, low cottonseed with steam-flaked corn $(\bullet)$, and medium cottonseed with steamflaked corn $(\mathbf{\Lambda})$.

Therefore, the NDF digestibilities estimated using equation [5], determined with or without the assumption of equality of $\mathrm{k}_{\mathrm{p}}$ of INDF and DNDF, were compared to NDF digestibilities calculated using duodenal flow measurements [(NDF intake - NDF flow)/NDF intake]. The residuals of NDF digestibilities calculated using duodenal flow (Harvatine et al., 2002) minus those obtained with the flux procedure (equation [5]) were graphed against the NDF digestibility based on duodenal flow with the assumption that the $\mathrm{k}_{\mathrm{p}}$ of INDF could be substituted for the $k_{p}$ of DNDF (Figure 2) or using the actual $k_{p}$ of DNDF (Figure 3). The regression lines were fit using simple linear regression using least squares analysis.

Ruminal fluid Co concentrations were corrected for 0 -h background effect. The Co concentration at time $t$ $\left(\mathrm{Co}_{\mathrm{t}}\right)$ was fit to the biexponential equation $\mathrm{Co}_{\mathrm{t}}=\mathrm{Ae}^{-\alpha t}$ $+\mathrm{Be}^{-\beta \mathrm{t}}$ or to a single exponential model using SAAM II (1997). A monoexponential model $(n=5)$ was estimated 


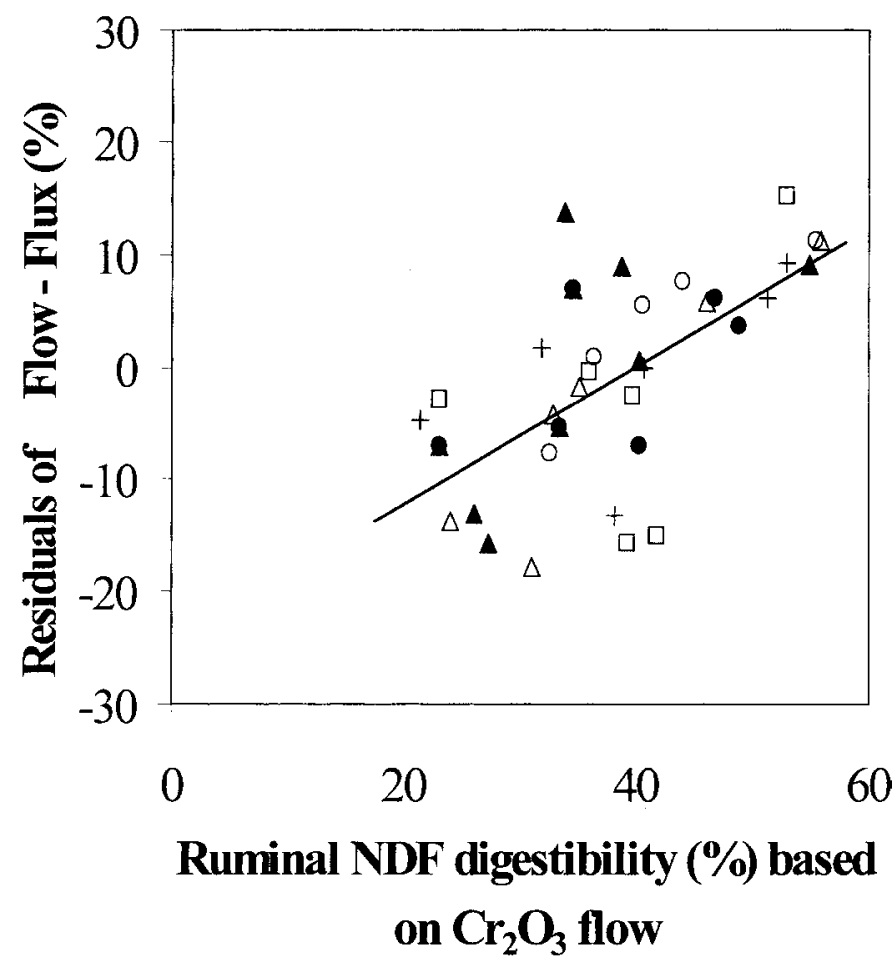

Figure 3. Plot of the residuals of NDF digestibility (\%) calculated based on flow of total NDF at the duodenum using $\mathrm{Cr}_{2} \mathrm{O}_{3}$ as a digesta marker and flux of potentially digestible NDF (DNDF). The passage rate of DNDF was estimated using equation [3], and the passage rate of DNDF was used in equations [4] and [5]. $\mathrm{y}=0.62 \mathrm{x}(\mathrm{SE}=0.13)-$ $24.4(\mathrm{SE}=5.1)$. Symbols represent the following treatments: forage control with ground corn $(+)$, low cottonseed with ground corn $(O)$, medium cottonseed with ground corn $(\triangle)$, high cottonseed with ground corn $(\square)$, low cottonseed with steam-flaked corn $(\bullet)$, and medium cottonseed with steam-flaked corn $(\mathbf{\Delta})$.

when the algorithm failed to converge with the biexponential model. Data for one cow during period 1 were removed because the data could not be fit to a monoexponential or biexponential model. The lack of fit was most likely due to incomplete mixing of the Co dose or nonrepresentative ruminal samples because of that cow's thick ruminal mat. Passage rate of $\mathrm{Yb}$ was done as for Co except that all $\mathrm{Yb}$ concentrations (corrected for background and calculated per $\mathrm{g}$ of sample DM) followed a monoexponential model.

For the data that fit the monoexponential model, the first-order rate $\alpha$ corresponds to the rate of passage of Co from the rumen, which is assumed to represent ruminal fluid dilution rate in a one-compartment model. For the remaining data that fit biexponential dilution, a two-compartment model was derived (Figure 4). The volume of compartment 1 (v1) was solved as the dose of Co divided by the sum of A plus B. Then the fractional transfer rates among compartments were calculated.

\section{Co Dose}

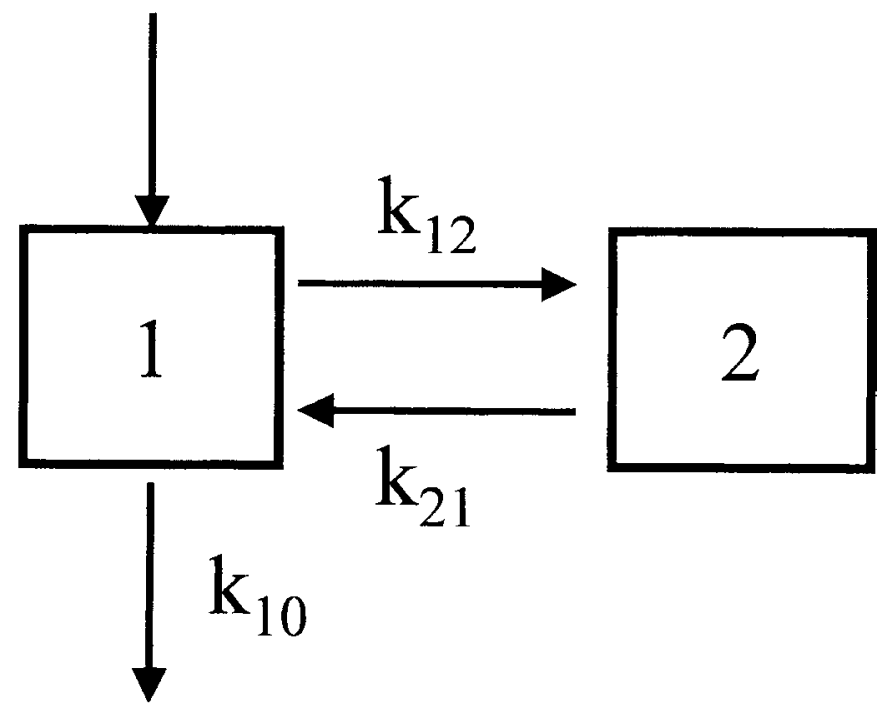

\section{Co Passage}

Figure 4. A schematic representation depicting fractional rates of transfer (k) of CoEDTA to and from two compartments of ruminal fluid.

$$
\begin{gathered}
\mathrm{k}_{10}=\operatorname{dose} /(\mathrm{v} 1 \cdot(\mathrm{A} / \alpha+\mathrm{B} / \beta)) \\
\mathrm{k}_{21}=\alpha \cdot \beta / \mathrm{k}_{10}
\end{gathered}
$$$$
\mathrm{k}_{12}=\alpha+\beta-\mathrm{k}_{10}-\mathrm{k}_{21}
$$

The $\mathrm{k}_{10}$ is interpreted to approximate fluid dilution rate from the rumen (Figure 4).

\section{Statistical Analyses}

Data were analyzed as a Latin square with cow as a random effect using the MIXED procedure of SAS (1999) as described previously (Harvatine et al., 2002). Significant differences were declared at $P<0.05$ unless otherwise stated. When the MIXED procedure failed to converge [eating, ruminating, and total chewing time (all minutes per day) and ruminating time (minutes per kilogram of FNDF)], data were analyzed using Proc GLM (SAS, 1999), with cow assumed to be a fixed effect. Ruminal mat consistency data were analyzed over time using a repeated measures model using the MIXED procedure of SAS. First-order autoregressive [AR(1)] was used as the covariance structure residuals within 
cow $\times$ period. When interactions of treatment $\times$ time were not deemed to be significant $(P \geq 0.10)$, averages over all times were analyzed for treatment effects.

The equations developed by Mooney and Allen (1997) to calculate coefficients for physical effectiveness of fiber were modified to calculate an effectiveness value for cotton NDF (CNDF; linted WCS plus linted cottonseed hulls). Individual cow observations for all treatments $(\mathrm{n}=35)$ were used. Total chewing times were adjusted by subtracting the assumed basal chewing time [355 $\mathrm{min} / \mathrm{d}$; calculated by Mooney and Allen (1997)] from the observed total chewing time (ruminating plus eating) because the model would not solve when our individual observations were used to estimate basal chewing time. The MIXED procedure of SAS (1999) was used to analyze factors relating to effective fiber for CNDF and alfalfa silage NDF using the following model:

$$
\mathrm{Y}_{\mathrm{ijk}}=\mathrm{Cow}_{\mathrm{i}}+\mathrm{Per}_{\mathrm{j}}+\beta_{1} \mathrm{FNDF}+\beta_{2} \mathrm{CNDF}+\mathrm{e}_{\mathrm{ijk}}
$$

where $\mathrm{Y}_{\mathrm{ijk}}=$ corrected chewing time, $\mathrm{Cow}_{\mathrm{i}}=$ random effect of ith cow, Per $_{j}=$ random effect of $j$ th period, $\beta_{1}$ $=$ regression coefficient for chewing time (minutes per kilogram) of alfalfa silage NDF, FNDF = alfalfa silage NDF intake (kilograms per day), $\beta_{2}=$ regression coefficient for chewing time (minutes per kilogram) of CNDF intake, $\mathrm{CNDF}=\mathrm{CNDF}$ intake (kilograms per day), and $\mathrm{e}_{\mathrm{ijk}}=$ random error $\sim \mathrm{N}\left(0, \sigma_{\mathrm{e}}^{2}\right)$. The $\mathrm{SE}$ of the ratio of $\beta_{2} / \beta_{1}$ was estimated using the following formula (Kendall and Stuart, 1969):

$$
\mathrm{V}\left(\mathrm{y}_{2} / \mathrm{y}_{1}\right)=\left(\mu_{2}^{2} \sigma_{1}^{2}+\mu_{1}^{2} \sigma_{2}^{2}-2 \mu_{1} \mu_{2} \sigma_{12}\right) / \mu_{1}^{4}
$$

where $\mathrm{V}\left(\mathrm{y}_{2} / \mathrm{y}_{1}\right)=$ variance of $\beta_{2} / \beta_{1} ; \mu_{2}=$ mean of $\beta_{2} ; \sigma_{1}{ }^{2}$ $=$ variance of $\beta_{1} ; \mu_{1}=$ mean of $\beta_{1} ; \sigma_{2}{ }^{2}=$ variance of $\beta_{2}$; and $\sigma_{12}=$ covariance of $\beta_{1}$ and $\beta_{2}$. There was a correlation of -0.3057 between $\beta_{1}$ and $\beta_{2}$. The means, variances, covariance and correlation estimates were obtained using Proc MIXED (SAS, 1999).

\section{RESULTS AND DISCUSSION}

\section{Chewing Activity}

Eating, ruminating, and total chewing activity, expressed as minutes per day, did not differ across diets (Table 1). Eating time increased as WCS replaced forage when expressed per unit of FNDF but not per unit of FNDF + CNDF. Although ruminating time tended $(P<0.10)$ to have quadratic effects when expressed per DM or NDF intake, total chewing time tended to decrease linearly $(P<0.11)$ when expressed per unit of DM or NDF intake. Quadratic responses to level of WCS for ruminating and total chewing times per unit of FNDF intake remained significant ( $P=0.04$ for both). These data, combined with the lack of effect in total chewing time per unit of FNDF + CNDF intake, indicate that the CNDF appears to be nearly as effective as NDF from alfalfa silage in maintaining chewing activity in low forage diets. In prior studies, the replacement of FNDF with NDF from WCS promoted more chewing than NDF from short-cut alfalfa silage but resulted in less chewing than long-cut alfalfa silage (Mooney and Allen, 1997); NDF from WCS maintained chewing activity similar to that of a $21 \%$ FNDF control in another study (Slater et al., 2000).

The substitution of SF for G corn did not interact with WCS substitution for FNDF or have any significant effect on chewing activity. Although true ruminal digestibility of both nonstructural carbohydrates and OM were increased, ruminal $\mathrm{pH}$ was not affected by the substitution of SF for G corn in L and M WCS diets, although DMI was reduced (Harvatine et al., 2002). This suggests that CNDF stimulates sufficient chewing activity to produce enough salivary buffers to compensate for the increased acid production associated with ruminal degradation of SF corn.

Chewing coefficients were calculated for FNDF and CNDF using multiple regression of various factors regressed against total chewing time corrected for basal chewing time using equation [9]. Cottonseed hulls were added to the diets in slightly different amounts during each period to balance NDF and enable the replacement of alfalfa silage NDF with CNDF on a one-to-one basis as alfalfa silage NDF varied during periods. The ratio of WCS to cottonseed hulls was, on average, 10 parts WCS to one part cottonseed hulls. As a result, it was not possible to isolate the individual effects of WCS and cottonseed hulls on chewing. Because previous researchers (Clark and Armentano, 1993; Mooney and Allen, 1997) have shown a significant contribution for the effective fiber from WCS based on total chewing response, both FNDF and CNDF were included in the multiple regression using procedures described by Firkins et al. (2001). The effect of treatment and the quadratic term $(\mathrm{CNDF} \times \mathrm{CNDF})$ were not significant $(P>$ $0.10)$ and were removed. When the quadratic term $($ FNDF $\times$ FNDF) was used in the model with CNDF and FNDF, the effect of CNDF became nonsignificant $(P>0.10)$. The quadratic term $(\mathrm{FNDF} \times \mathrm{FNDF})$ was excluded rather than the effect of CNDF based on our preplanned objectives to quantify the effectiveness of CNDF. The final model included the random effects of cow and period and the fixed effects of FNDF and CNDF intakes, all of which were significant $(P<0.05)$. Chewing coefficients were calculated based on FNDF and CNDF intakes (kilograms per day) rather than percentages of the diets (Mooney and Allen, 1997) because 
Table 1. Least squares means for chewing responses by cows fed diets in which whole cottonseed replaced alfalfa silage and was fed with ground or steam-flaked corn.

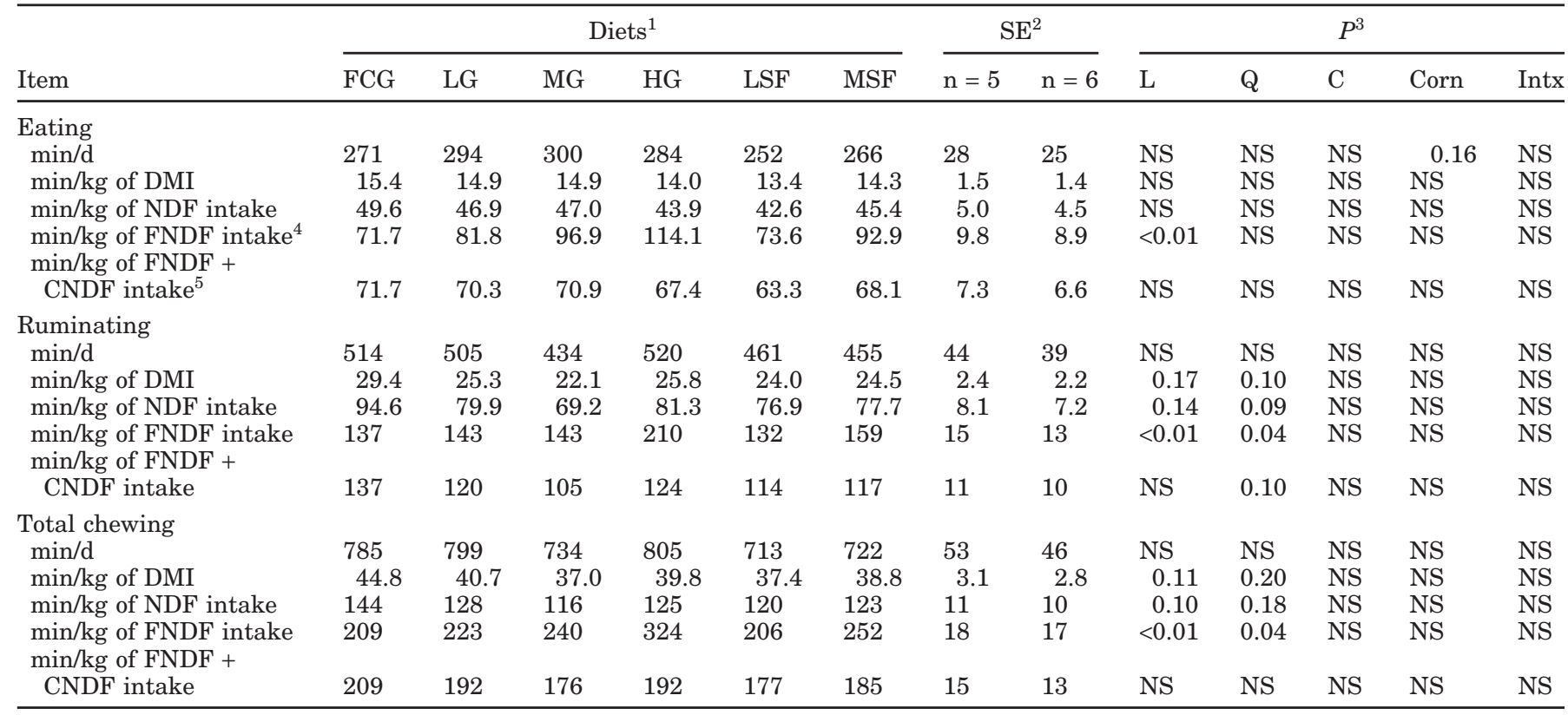

${ }^{1} \mathrm{FCG}=$ Forage control with ground corn $\mathrm{LG}=$ low cottonseed with ground corn; $\mathrm{MG}=$ medium cottonseed with ground corn; HG = high cottonseed with ground corn; LSF = low cottonseed with steam-flaked corn, and MSF = medium cottonseed with steam-flaked corn.

${ }^{2}$ For the LG treatment $\mathrm{n}=5$; for all other treatments $\mathrm{n}=6$.

${ }^{3}$ Probability of a treatment response; NS $=$ not significant $(P>0.20)$. Contrasts compared the linear $(\mathrm{L})$, quadratic $(\mathrm{Q})$, and cubic $(\mathrm{C})$ effects of increasing level of whole cottonseed in the diet when ground corn was used as the corn source (FCG, LG, MG, and HG). Contrast Corn compared the effect of corn source (ground vs. steam-flaked) when low or medium levels of cottonseed were fed (LG and MG vs. LSF and MSF). Contrast Intx evaluated the interaction of corn source (ground or steam-flaked) and level of cottonseed (low or medium) in LG, MG, LSF, and MSF treatments.

${ }^{4} \mathrm{FNDF}=\mathrm{NDF}$ from forage.

${ }^{5} \mathrm{CNDF}=\mathrm{NDF}$ from cotton products (whole linted cottonseed and linted cottonseed hulls).

there was a treatment effect for both DMI and NDF intake (Harvatine et al., 2002).

With the model specified by equation [9], the regression coefficients were estimated to be $97.1 \mathrm{~min} / \mathrm{kg}$ of FNDF ( $\mathrm{SE}=13.5)$ and $82.0 \mathrm{~min} / \mathrm{kg} \mathrm{CNDF}(\mathrm{SE}=30.2)$. The physical effectiveness factor for CNDF relative to FNDF would be $\left(\beta_{2} / \beta_{1}\right)$ or 0.84 (asymptotic $\mathrm{SE}=0.36$ ). Thus, the NDF from CNDF was estimated to be $84 \%$ as effective as NDF from alfalfa silage in stimulating chewing activity. Because of its high asymptotic SE, which resulted from compounding variation from both slope estimates, the physical effectiveness factor of WCS is not different $(P>0.05)$ from 1.0, explaining the similar chewing activity (minutes per day) across diets. Mooney and Allen (1997) calculated a physical effectiveness factor of NDF from WCS to be 0.50 and 1.27 when long- or short-cut alfalfa silages, respectively, were used as the standards; these had mean NDF particle sizes of 11.4 and $5.8 \mathrm{~mm}$, respectively. The alfalfa silage used in this study had a mean DM particle size of $5.6 \mathrm{~mm}$, as determined by wet sieving (Harvatine et al., 2002).
Grant (1997) noted that rumination per unit of FNDF intake often increased when the dietary NDF concentration was reduced; these observations, including the current quadratic responses of ruminating and total chewing time per unit of FNDF (Table 1), suggest that cows may possess an adaptive mechanism whereby they ruminate more efficiently under conditions of limited amounts of effective fiber. However, by design, there was a linear decrease in FNDF and a linear increase in CNDF as CNDF replaced FNDF in the current study, so it is not possible to determine whether the cows responded to low FNDF diets by chewing more efficiently independent from CNDF effects.

Because the basal chewing time used in the model was not determined with values from this study, the effect of varying basal chewing time was considered. Reducing the basal chewing time from 355 to $250 \mathrm{~min} /$ $\mathrm{d}$ increased the regression coefficients to $123 \mathrm{~min} / \mathrm{kg}$ of FNDF and $102 \mathrm{~min} / \mathrm{kg}$ of $\mathrm{CNDF}$, whereas increasing the basal chewing time from 355 to $450 \mathrm{~min} / \mathrm{d}$ reduced the regression coefficients to 74 and $64 \mathrm{~min} / \mathrm{kg}$ of FNDF 
Table 2. Least squares means for ruminal mat consistency for cows fed diets in which whole cottonseed replaced alfalfa silage and was fed with ground or steam-flaked corn.

\begin{tabular}{|c|c|c|c|c|c|c|c|c|}
\hline \multirow[b]{2}{*}{ Item } & \multicolumn{6}{|c|}{$\operatorname{Diets}^{1}$} & \multicolumn{2}{|c|}{$\mathrm{SE}^{2,3}$} \\
\hline & FCG & LG & MG & HG & LSF & MSF & $\mathrm{n}=5$ & $\mathrm{n}=6$ \\
\hline \multicolumn{9}{|c|}{ Total distance traveled, $\mathrm{cm}$} \\
\hline $1 \mathrm{~min}$ & 15.0 & 14.6 & 12.7 & 16.5 & 12.4 & 11.9 & 3.5 & 3.2 \\
\hline $2 \min$ & 20.5 & 21.3 & 18.2 & 23.9 & 17.7 & 18.7 & 4.3 & 4.0 \\
\hline $5 \min$ & 31.9 & 33.0 & 28.1 & 36.3 & 27.7 & 30.0 & 4.8 & 4.4 \\
\hline $9 \mathrm{~min}$ & 40.9 & 42.2 & 36.2 & 45.1 & 40.0 & 38.6 & 4.8 & 4.4 \\
\hline \multicolumn{9}{|c|}{ Cumulative ascension rate, $\mathrm{cm} / \mathrm{s}$} \\
\hline First min & 0.25 & 0.24 & 0.21 & 0.27 & 0.21 & 0.20 & 0.06 & 0.05 \\
\hline First 2 min & 0.17 & 0.18 & 0.15 & 0.20 & 0.15 & 0.16 & 0.04 & 0.03 \\
\hline First $5 \mathrm{~min}$ & 0.11 & 0.11 & 0.09 & 0.12 & 0.09 & 0.10 & 0.02 & 0.01 \\
\hline First $9 \mathrm{~min}$ & 0.076 & 0.078 & 0.067 & 0.083 & 0.074 & 0.072 & 0.009 & 0.008 \\
\hline
\end{tabular}

${ }^{1} \mathrm{FCG}=$ Forage control with ground corn; $\mathrm{LG}=$ low cottonseed with ground corn; $\mathrm{MG}=$ medium cottonseed with ground corn; HG = high cottonseed with ground corn; LSF = low cottonseed with steam-flaked corn, and MSF = medium cottonseed with steam-flaked corn.

${ }^{2}$ For the LG treatment $\mathrm{n}=5$; for all other treatments $\mathrm{n}=6$.

${ }^{3}$ None of the contrasts were significant $(P>0.20)$.

and CNDF. However, the physical effectiveness factor did not change considerably when basal chewing time was changed (0.83 and 0.87 ). This demonstration documents the relatively high confidence in the accuracy of the physical effectiveness of a test feed (i.e., $\beta_{2} / \beta_{1}$ in equation [9]) rather than the absolute regression coefficients (i.e., $\beta_{1}$ or $\beta_{2}$ ) but illustrates the importance of documentation and standardization of the test forages when comparing physical effectiveness values among studies.

\section{Ruminal Mat Consistency}

Ruminal mat consistency did not differ across treatments (Table 2). Ruminal mat consistency decreased when FNDF was replaced with NDF from nonforage fiber sources without coarsely chopped hay (Weidner and Grant, 1994a; Allen and Grant, 2000). Reduced ruminal mat consistency probably decreased total chewing time when wet corn gluten feed was used as a forage replacer (Allen and Grant, 2000). These results (Table 2) also support the adaptive response of WCS fiber in maintenance of ruminating and chewing activities (min/d; Table 1) across treatments and the greater response for WCS than other byproducts.

\section{Passage Kinetics of NDF}

The DM and NDF percentages of the ruminal digesta increased linearly with increasing level of WCS substitution for forage (Table 3). Ruminal mass of wet digesta did not differ across treatments; however, the mass of rumen DM, OM, NDF, INDF, and DNDF increased linearly with increasing level of WCS addition. There was a quadratic response in DMI: 17.8, 19.8, 20.5, and
$20.3 \mathrm{~kg} / \mathrm{d}$ for FCG, LG, MG, and HG, respectively (Harvatine et al., 2002). The differences in rumen pool sizes of DM and fiber probably explain the lack of differences in ruminal mat consistency (Table 2). Replacement of FNDF with NDF from nonforage fiber sources other than WCS has reduced ascension time (i.e., reduced ruminal mat consistency) in past studies (Weidner and Grant, 1994a; Allen and Grant, 2000). Therefore, increased ruminal DM mass seemed to have provided resistance to ascension of the ruminal weight that counteracted the decrease in mat consistency resulting from decreased forage. Increased ruminal mass appeared to have stimulated tension receptors (Allen, 2000) or provided enough tactile stimulation to maintain similar chewing time as CNDF replaced FNDF (Table 1).

The $\mathrm{k}_{\mathrm{p}}$ of INDF (Table 3) was calculated based on the flux technique (see footnote 5) presented by Dado and Allen (1995) or based on duodenal flow of INDF (see footnote 6). The similarity in intake and duodenal flow of INDF within treatments supports the use of INDF intake to calculate $\mathrm{k}_{\mathrm{p}}$ of INDF and explains why both calculation methods yielded similar values for $\mathrm{k}_{\mathrm{p}}$ of INDF.

A key assumption for using the flux technique to alleviate duodenal sampling is that the $k_{p}$ of INDF should approximate the $\mathrm{k}_{\mathrm{p}}$ of DNDF, assuming that both fractions are found in the same physical particle. However, DNDF and INDF are determined from a conglomerated mix of particles with varying DNDF and INDF concentrations. Assuming that the $\mathrm{k}_{\mathrm{p}}$ of the particle might not be linearly related with the percentage of total NDF that is comprised by DNDF, this assumption of equivalent $k_{p}$ of DNDF and INDF might not be valid (see Figure 1). 
Table 3. Least squares means for ruminal pool sizes and ruminal digestion kinetics for cows fed diets in which whole cottonseed replaced alfalfa silage and was fed with ground or steam-flaked corn.

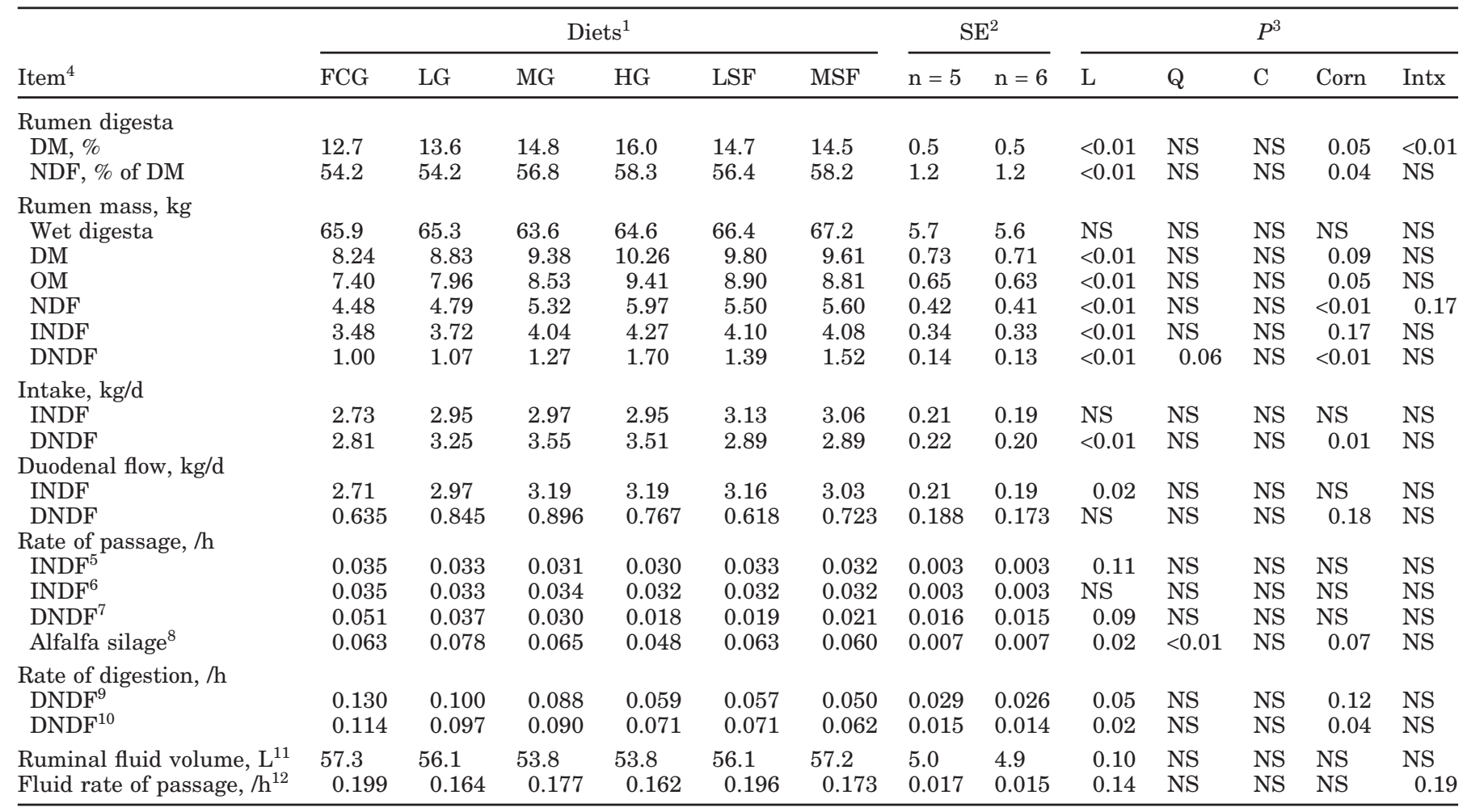

${ }^{1} \mathrm{FCG}=$ Forage control with ground corn; $\mathrm{LG}=$ low cottonseed with ground corn; $\mathrm{MG}=$ medium cottonseed with ground corn; HG = high cottonseed with ground corn; LSF= low cottonseed with steam-flaked corn, and MSF = medium cottonseed with steam-flaked corn.

${ }^{2}$ For the LG treatment $\mathrm{n}=5$; for all other treatments $\mathrm{n}=6$.

${ }^{3}$ Probability of a treatment response; NS $=$ not significant $(P>0.20)$. Contrasts compared the linear $(\mathrm{L})$, quadratic $(\mathrm{Q})$, and cubic $(\mathrm{C})$ effects of increasing level of whole cottonseed in the diet when ground corn was used as the corn source (FCG, LG, MG, and HG). Contrast Corn compared the effect of corn source (ground vs. steam-flaked) when low or medium levels of cottonseed were fed (LG and MG vs. LSF and MSF). Contrast Intx evaluated the interaction of corn source (ground or steam-flaked) and level of cottonseed (low or medium) in LG, MG, LSF, and MSF treatments.

${ }^{4} \mathrm{INDF}=$ Indigestible NDF determined by 120 -h in vitro fermentation, and DNDF $=$ potentially digestible NDF (NDF - INDF).

${ }^{5}$ Fractional passage rate of INDF based on intake of INDF. See equation [1].

${ }^{6}$ Fractional passage rate of INDF based on duodenal flow of INDF. See equation [2].

${ }^{7}$ Fractional passage rate of DNDF based on duodenal flow of DNDF. See equation [3].

${ }^{8}$ Fractional passage rate of alfalfa silage from the rumen using $\mathrm{Yb}$ as a marker.

${ }^{9}$ Fractional digestion rate of DNDF calculated using equation [4] but assuming that passage rate of INDF (from equation [1]) equals the passage rate of DNDF (Dado and Allen, 1995) (substituted for the result from equation [3]).

${ }^{10}$ Fractional digestion rate of DNDF calculated using equation [4] and using the actual fractional passage rate of DNDF from equation [3].

${ }^{11}$ Ruminal fluid $=$ wet digesta mass $-\left(55^{\circ} \mathrm{C} \mathrm{DM} *\right.$ wet digesta mass $)$.

${ }^{12}$ Determined using Co-EDTA to mark the fluid portion of ruminal contents.

When $\mathrm{k}_{\mathrm{p}}$ of INDF and DNDF were calculated using duodenal flows (see footnotes 6 and 7 of Table 3), the $\mathrm{k}_{\mathrm{p}}$ of INDF was not affected, but the $\mathrm{k}_{\mathrm{p}}$ of DNDF tended to decrease linearly from 0.051 to $0.018 / \mathrm{h}$ as $\mathrm{CNDF}$ replaced alfalfa silage NDF. Because DNDF contributes to particle buoyancy and retention in the rumen, Firkins et al. (1998) suggested that $k_{p}$ of INDF should be faster than the $k_{p}$ of DNDF, but the current results refute this assumption or narrow it to comparisons among forage sources.
Our results support the suggestion that WCS are retained in the ruminal mat through entanglement of WCS linters with longer forage particles, which would slow the passage rate of WCS (Coppock et al., 1985). Bhatti and Firkins (1995) reported that the functional specific gravity of ground cottonseed hulls remained relatively unchanged over $27 \mathrm{~h}$ of in vitro incubation, but they had a fast rate of hydration, implying little buoyancy delay of the ground cottonseed hulls. However, little information related to passage kinetics of 
WCS is available. The passage rate of alfalfa silage (determined by $\mathrm{Yb}$ ) decreased linearly with increasing level of WCS inclusion (Table 3). In previous studies with soybean hulls (Weidner and Grant, 1994a) and wet corn gluten feed (Allen and Grant, 2000), forages and nonforage fiber sources interacted to decrease the $k_{p}$ of the nonforage fiber sources; however, it is not clear whether the $k_{p}$ of forage was also affected in these studies. Wattiaux et al. (1992) reported that alfalfa silage reached a functional specific gravity conducive for passage faster than did alfalfa hay because the former was prehydrated, and WCS could thereby help to slow the passage of alfalfa silage particles through entanglement (rather than vice versa). The increasing DM percentage with increasing WCS (Table 3) also supports our contention that particle entanglement of WCS helped slow passage. An alternative explanation is that the decreasing $\mathrm{k}_{\mathrm{p}}$ of $\mathrm{Yb}$-marked alfalfa silage could be a result of $\mathrm{Yb}$ migration to slower passing WCS particles. Alfalfa NDF decreased from 70 to $39 \%$ of total NDF with increasing WCS (data not shown). Firkins et al. (1998) noted that typical markers, such as Yb, often overestimate ruminal passage rate through migration, although procedures similar to those used in this experiment can reduce migration (Bernard and Doreau, 2000).

The dilution of $\mathrm{Yb}$ concentration after dosing of $\mathrm{Yb}$ labeled WCS was extremely variable. None of the models tested for any of the 35 datasets could be estimated (lack of convergence of the optimization algorithm). The linters apparently prevented the WCS dose from being mixed or diluted well, providing observational corroboration to the significant entanglement and retention of WCS.

When the $k_{d}$ of DNDF was calculated using the $k_{p}$ of INDF (footnote 9) or the $k_{p}$ of DNDF (footnote 10), the SE almost doubled for the INDF assumption (Table 3). However, there was a numerically larger linear effect of increasing WCS addition when the $\mathrm{k}_{\mathrm{p}}$ of INDF was substituted for the $\mathrm{k}_{\mathrm{p}}$ of DNDF. Bhatti and Firkins (1995) reported that ground alfalfa had a higher rate of digestion (0.0547 compared with $0.0208 \mathrm{~h}^{-1}$ ) and shorter lag time in vitro than ground cottonseed hulls. Palmquist (1995) noted that cotton linters were not degraded in the first 12 to $16 \mathrm{~h}$ of incubation in situ or in vitro; degradation increased linearly thereafter to achieve $90 \%$ digestibility after 96 to $120 \mathrm{~h}$ of incubation. The flux technique assumes no lag time, so a longer lag time would decrease the $\mathrm{k}_{\mathrm{d}}$ of DNDF using the current procedure.

Despite a $1.2 \mathrm{~kg} / \mathrm{d}$ lower DMI (Harvatine et al., 2002), the mass of OM, NDF, and DNDF increased when SF corn replaced G corn (Table 3). Because digestibility of $\mathrm{OM}$ was increased and that of NDF was unchanged by $\mathrm{SF}$ addition (Harvatine et al., 2002), these results appear to be related to the larger volume taken by SF than $\mathrm{G}$ corn or to trends for slower $\mathrm{k}_{\mathrm{p}}$ of alfalfa and slower $k_{d}$ of DNDF for SF versus G corn.

Ruminal NDF digestibility based on NDF flux (equation [5]) compared with NDF digestibility based on duodenal flow of NDF resulted in a positive linear bias that was stronger (higher slope and more negative intercept) when the $k_{p}$ of INDF was substituted for the $k_{p}$ of DNDF (Figure 2) than when the actual $k_{p}$ of DNDF was used directly (Figure 3 ). The average ruminal NDF digestibility was numerically similar for estimates based on duodenal flow of NDF using $\mathrm{Cr}_{2} \mathrm{O}_{3}$ [ $(38.3 \%$; see (Harvatine et al., 2002)] and estimates based on $\mathrm{k}_{\mathrm{p}}$ of DNDF (39.4\%; data from Figure 3) than based on the $k_{p}$ of INDF (35.8\%; data from Figure 2). The bias between NDF digestibilities (Figures 2 and 3) could be a result of errors in duodenal flow estimation using $\mathrm{Cr}_{2} \mathrm{O}_{3}$ or to the assumptions used (Firkins et al., 1998). However, duodenal flow of NDF is the net result of all kinetic events, whereas the flux techniques used in our study are based on a single compartment model (i.e., only one pool of DNDF) with no delay (lag) terms affecting either digestion or passage. If more than one compartment or delay term exist, they are aggregated into the simple model assumed by the flux technique.

\section{Passage Kinetics of Ruminal Fluid}

When ruminal fluid volume was measured using rumen evacuation, ruminal fluid volume tended $(P=0.10)$ to decrease linearly with increasing WCS (Table 3 ). However, there were no differences in fluid rate of passage (Table 3).

The single rate of Co dilution $(\alpha)$ from data that fit best a monoexponential model (Co concentration at time $\left.\mathrm{t}=\mathrm{Ae}^{-\alpha \mathrm{t}}\right)$ ranged from 0.131 to $0.178 / \mathrm{h}$ and averaged $0.148 / \mathrm{h}(\mathrm{n}=5)$. The $\mathrm{k}_{10}$ data from the two-compartment model (Figure 4) ranged from 0.129 to 0.296 and averaged $0.186 / \mathrm{h}(\mathrm{n}=29)$. Because the effect of passage rate model (one or two compartments) was $P>0.10$ when added as a fixed effect into the statistical model (data not shown), a data file with combined $\alpha$ and $\mathrm{k}_{10}$ (and no effect of model choice) was evaluated statistically to compare effects of treatment on ruminal fluid dilution rate (Table 3). These mean dilution rates for treatments are higher than data typically reported because most researchers ignore the potential contribution of a first exponential term. However, in two previous studies (Younker et al., 1998; Oldick et al., 2000), similar high values for weighted dilution rates were reported when data were fit to biexponential models. Using $\mathrm{k}_{10}$ to estimate ruminal fluid dilution rate probably is more theoretically appropriate than using a single 
weighted average of $\alpha$ and $\beta$ as done by the previous authors because it integrates differential equations describing transfer to and from compartments.

For the five observations using a one-compartment model, ruminal fluid volume (dose of $\mathrm{Co} / \mathrm{A}$ ) averaged 59\% higher than the volumes estimated using rumen evacuation. Overestimation of total fluid volume compared with evacuation could be partially explained by tactile stimulation of passage of fluid during evacuation or by incomplete rumen evacuation. However, it seems unlikely that these errors could accumulate to 59\%, thereby decreasing the likelihood that a one-compartment model adequately describes ruminal fluid kinetics.

Because the compartments were not sampled separately, elimination of Co using the two-compartment model was constrained to compartment 1 , all samples were assumed to have been all from this pool, and v1 was estimated as the Co dose/(A+B). Assuming instantaneous mixing of Co and steady-state conditions, the volume of compartment 2 (v2) could be solved as v1 $\times$ $\mathrm{k}_{12} / \mathrm{k}_{21}$. When the $\mathrm{v} 1$ and $\mathrm{v} 2$ were summed per animal (data not shown; $\mathrm{n}=34$ ), the combined total volume averaged $90.9 \mathrm{~L}$, which is $64 \%$ higher than the total ruminal fluid volume determined by evacuation ( 55.5 L). However, when four extreme data were removed (n $=30$ ), then the total volume of v1 plus v2 averaged 66.6 L (data not shown), which still overestimated evacuation data by $20 \%$.

Overestimation of total fluid volume (v1 plus v2), particularly for the four observations, compared with evacuation could be partially explained by underestimated evacuation volumes. However, a more likely explanation is related to sampling error at early times after dosing. Delayed distribution of CoEDTA throughout both compartments after dosing would have a larger impact on the accuracy and precison of the measurements used to derive the first exponential term because much of the flux of Co between compartments 1 and 2 would be occurring in a relatively short time after dosing. In fact, 15 and 8 samples (out of 34) taken at 20 and 40 min postdosing, respectively, were outliers that needed to be deleted. Assuming the evacuation data to be correct and the second exponential term to have much less sampling error (data were spread over a longer time after dosing), the A term was apparently underestimated, leading to overestimation of v1. Because v2 was solved using an algebraic equation in which $\mathrm{v} 2$ is directly proportional to $\mathrm{v} 1$, it follows that the v2 would also be overestimated proportionally, further compounding the error when Co-derived ruminal fluid volume (v1 plus v2) was compared to the manually determined fluid volume. Although further verification of a two-compartment model is needed, it seems more appropriate than using a single compartment model. The significant fit of Co data to biexponential models for 29 of 34 observations supports this contention. From these 29 solutions, the $\beta$ rates averaged $0.056 / \mathrm{h}$ (data not shown), which would be an unreasonably low estimate for fluid dilution rate but would be increased if data were aggregated into a single exponential model. The rate of elimination of Co from the rumen $\left(\mathrm{k}_{10}\right.$ in Figure 4) is calculated using Equation [6]. If v1 is calculated as dose $(\mathrm{A}+\mathrm{B})$, and the latter is substituted into equation [6], then

$$
\mathrm{k}_{10}=(\mathrm{A}+\mathrm{B}) /(\mathrm{A} / \alpha+\mathrm{B} / \beta)
$$

Thus, the errors related to data fitting would tend to cancel (A is on the numerator and denominator [11], although $\mathrm{A}$ and $\alpha$ are potentially correlated positively) rather than amplify as when used to estimate ruminal fluid volume. Thus, we conclude that a two-compartment model should be evaluated for potential use to more accurately estimate fluid dilution rate from the rumen. In future experiments, improved distribution of dose (better manual mixing), more time points, and improved sampling procedures could be used to improve the accuracy of determination of true fluid dilution rate from the rumen.

The biological meaning of these two compartments should be interpreted with caution until both compartments can be sampled simultaneously (the current procedure assumed sampling from compartment 1 only). However, we suggest that compartment 1 is fluid that is immediately capable of exiting the rumen, but compartment 2 is fluid that is associated within or immediately surrounding particles that are retained in the rumen until hydration and digestion are completed to allow the particles (and associated fluid) to have a functional specific gravity that promotes passage (Firkins et al., 1998).

\section{CONCLUSIONS}

Based on total chewing activity, CNDF appeared to be approximately $84 \%$ as effective in stimulating chewing as the alfalfa silage NDF used in this experiment. Thus, there is potential to use WCS at up to $15 \%$ of DM to maintain chewing activity in low FNDF diets. Passage and digestion properties of WCS and apparent interactions among WCS and alfalfa silage for passage from the rumen appeared to help maintain ruminal mat consistency and chewing activity as WCS replaced alfalfa silage. Lack of an interaction between WCS and starch source for measures of effectiveness suggests that the effective fiber response of WCS was independent of ruminal starch availability. 
Ruminal NDF digestion kinetics showed a bias for the flux technique determined without collection of duodenal digesta compared against the traditional duodenal flow technique, so more work is needed to compare estimations of ruminal NDF digestibility using the $k_{p}$ of INDF before this procedure adequately replaces traditional duodenal flow methods. In addition, more work is needed to validate the assumption of a single compartment model to assess ruminal fluid dilution rate; our work supports the development of a two-compartment model, especially to evaluate ruminal fluid volume using markers.

\section{REFERENCES}

Allen, D. M., and R. J. Grant. 2000. Interactions between forage and wet corn gluten feed as sources of fiber in diets for lactating dairy cows. J. Dairy Sci. 83:322-331.

Allen, M. S. 1997. Relationship between fermentation acid production in the rumen and the requirement for physically effective fiber. J. Dairy Sci. 80:1447-1462.

Allen, M. S. 2000. Effects of diet on short-term regulation of feed intake by lactating dairy cattle. J. Dairy Sci. 83:1598-1624.

Association of Official Analytical Chemists. 1990. Official Methods of Analysis. 15th. AOAC, Arlington, VA.

Bernard, L., and M. Doreau. 2000. Use of rare earth elements as external markers for mean retention time measurements in ruminants. Reprod. Nutr. Dev. 40:89-101.

Bhatti, S. A., and J. L. Firkins. 1995. Kinetics of hydration and functional specific gravity of fibrous feed by-products. J. Anim. Sci. 73:1449-1458.

Bowman, J. G. P., C. W. Hunt, M. S. Kerley, and J. A. Paterson. 1991. Effects of grass maturity and legume substitution on large particle size reduction and small particle flow from the rumen of cattle. J. Anim. Sci. 69:369-378.

Clark, P. W., and L. E. Armentano. 1993. Effectiveness of neutral detergent fiber in whole cottonseed and dried distillers grains compared with alfalfa haylage. J. Dairy Sci. 76:2644-2650.

Coppock, C. E., J. R. Moya, J. W. West, D. H. Nave, J. M. Labore, and C. E. Gates. 1985. Effect of lint on whole cottonseed passage and digestibility and diet choice on intake of whole cottonseed by Holstein cows. J. Dairy Sci. 68:1198-1206.

Dado, R. G., and M. S. Allen. 1995. Intake limitations, feeding behavior, and rumen function of cows challenged with rumen fill from dietary fiber or inert bulk. J. Dairy Sci. 78:118-133.

Ellis, W. C., C. Lascano, R. Teeter, and F. N. Owens. 1982. Solute and particulate flow markers. Pages 37-56 in Protein Requirements for Cattle: Symposium. F. N. Owens, ed. Oklahoma State Univ. Press, Stillwater.

Firkins, J. L. 1997. Effects of feeding nonforage fiber sources on site of fiber digestion. J. Dairy Sci. 80:1426-1437.
Firkins, J. L., M. S. Allen, B. S. Oldick, and N. R. St-Pierre. 1998. Modeling ruminal digestibility of carbohydrates and microbial protein flow to the duodenum. J. Dairy Sci. 81:3350-3369.

Firkins, J. L., M. L. Eastridge, N. R. St-Pierre, and S. M. Noftsger. 2002. Effects of grain variability and processing on starch utilization by lactating dairy cattle. Online. Available: http://www.asas.org/jas. J. Anim. Sci. 79 (E. Suppl.):E218-E238.

Grant, R. J. 1997. Interactions among forages and nonforage fiber sources. J. Dairy Sci. 80:1438-1446.

Harvatine, D. I., J. L. Firkins, and M. L. Eastridge. 2002. Whole linted cottonseed as a forage substitute fed with ground or steamflaked corn: Digestibility and performance. J. Dairy Sci. 85:1988-1999.

Kendall, M. G., and A. Stuart. 1969. The advanced theory of statistics. Vol. 1. Distribution theory. 3. Griffin, London.

Mertens, D. R. 1997. Creating a system for meeting the fiber requirements of dairy cows. J. Dairy Sci. 80:1463-1481.

Mooney, C. S., and M. S. Allen. 1997. Physical effectiveness of the neutral detergent fiber of whole linted cottonseed relative to that of alfalfa silage at two lengths of cut. J. Dairy Sci. 80:2052-2061.

National Research Council. 1989. Nutrient Requirements of Dairy Cattle. 6th rev. ed. Natl. Acad. Sci., Washington, DC.

Oldick, B. S., J. L. Firkins, and R. A. Kohn. 2000. Compartmental modeling with nitrogen-15 to determine effects of degree of fat saturation on intra-ruminal $\mathrm{N}$ recycling. J. Anim. Sci. 78:2421-2430.

Palmquist, D. L. 1995. Digestibility of cotton lint fiber and whole oilseeds by ruminal microorganisms. Anim. Feed Sci. Technol. 56:231-242.

Robinson, P. H., and McQueen, R. E. 1997. Influence of level of concentrate allocation and fermentability of forage fiber on chewing behavior and production of dairy cows. J. Dairy Sci. 80:681-691.

SAAM. 1997. SAAM II User Guide. Release 1.1. SAAM Inst., Seattle, WA.

SAS. 1999. What's New in SAS Software for Version 7 and the Version 8 Developer's Release. Release 7. SAS Inst., Cary, NC.

Slater, A. L., M. L. Eastridge, J. L. Firkins, and L. J. Bidinger. 2000. Effects of starch source and level of forage neutral detergent fiber on performance by dairy cows. J. Dairy Sci. 83:313-321.

Uden, P., P. E. Colucci, and P. J. Van Soest. 1980. Investigation of chromium, cerium and cobalt as markers in digesta rate of passage studies. J. Sci. Food Agric. 31:625-632.

Van Soest, P. J., J. B. Robertson, and B. A. Lewis. 1991. Methods for dietary fiber, neutral detergent fiber, and nonstarch polysaccharides in relation to animal nutrition. J. Dairy Sci. 74:35833597.

Wattiaux, M. A., L. D. Satter, and D. R. Mertens. 1992. Effect of microbial fermentation on functional specific gravity of small forage particles. J. Anim. Sci. 70:1262-1270.

Weidner, S. J., and R. J. Grant. 1994a. Altered ruminal mat consistency by high percentages of soybean hulls fed to lactating dairy cows. J. Dairy Sci. 77:522-532.

Weidner, S. J., and R. J. Grant. 1994b. Soyhulls as a replacement for forage fiber in diets for lactating dairy cows. J. Dairy Sci. 77:513-521.

Younker, R. S., S. D. Winland, J. L. Firkins, and B. L. Hull. 1998. Effects of replacing forage fiber or nonfiber carbohydrates with dried brewers grains. J. Dairy Sci. 81:2645-2656. 